\title{
人类活动和气候变化触发了中国西南石漠化的 扩张
}

陈朝军 ${ }^{1,2,3}$, 袁道先 ${ }^{1,2}$, 程海 ${ }^{4}$, Tsai Luen $\mathrm{YU}^{5,6}$, Chuan Chou SHEN ${ }^{5,6,7}$, R. Lawrence EDWARDS ${ }^{8}$, 吴尧 ${ }^{1}$, 肖思雅 ${ }^{1}$, 张键 ${ }^{1,9}$, 王涛 ${ }^{1}$, 黄舟 ${ }^{1}$, 刘子琦 ${ }^{10}$, 李廷勇 ${ }^{3 *}$, 李俊云 ${ }^{1,2 \dagger}$

1. 西南大学地理科学学院岩溶环境重点实验室, 重庆 400715;

2. 中国地质科学院岩溶地质研究所, 自然资源部/广西岩溶动力学重点实验室, 桂林 541004;

3. 云南师范大学地理学部, 云南省高原地理过程与环境变化重点实验室, 昆明 650500 ;

4. 西安交通大学全球环境变化研究院, 西安 710049;

5. 台湾大学地球科学系高精度质谱与环境变化实验室, 台北 10617 ;

6. 台湾大学未来地球研究中心, 台北 10617 ;

7. 台湾大学全球变化研究中心, 台北 10617 ;

8. Department of Earth Sciences, University of Minnesota, Minneapolis, MN 55455, USA;

9. Environnements et Paléoenvironnements Océaniques et Continentaux (EPOC), UMR CNRS, 5805, Université de Bordeaux, Pessac 33600, France; 10. 贵州师范大学喀斯特研究院, 贵阳 550001

* 通讯作者, E-mail: cdlity@163.com

$\dagger$ 通讯作者, E-mail: jxljy@swu.edu.cn

收稿日期: 2020-07-22; 收修改稿日期: 2021-02-23; 接受日期: 2021-03-19; 网络版发表日期: 2021-08-09

国家自然科学基金项目(批准号：41772170、42011530078)、中央高校基本科研业务费专项资金项目(编号：XDJK2017A010、 XDJK2020D005)、重庆市自然科学基金项目(编号：cstc2019yszx-jcyjX0002、cstc2020yszX-jcyjX0006)、广西岩溶动力学重大科技创新基地 开放课题(编号：KDL \& Guangxi 202003)、台湾科学先锋研究计划项目(编号：108-2119-M-002-012)、台湾高等教育萌芽工程项目(编号: 108L901001)和中国国家留学基金项目资助

摘要 研究石漠化扩张的机制, 有利于岩溶地区人与自然的可持续发展. 中国西南大面积的石漠化是受气候变化 还是人类活动的主导仍然存在争议. 通过贵州省石将军洞高精度的石笋 $\delta^{13} \mathrm{C}$ 记录, 本研究重建了过去2000年来中 国西南区域的石漠化演变. 从中世纪暖期到小冰期, 石将军洞石笋 $\delta^{13} \mathrm{C}$ 持续偏重; 在同一时期, 中国西南区域其他 石笋和钙华的 $\delta^{13} \mathrm{C}$ 记录都表现出同样显著偏重的趋势. 由于石笋 $\delta^{13} \mathrm{C}$ 记录能够反映洞穴上部的生态环境变化, 因 此中国西南区域石笋 $\delta^{13} \mathrm{C}$ 一致的变化可能反映了中国西南喀斯特地区石漠化扩张的过程. 中世纪暖期亚洲夏季 风加强, 雨带北移, 导致了中国西南千旱, 北方湿润; 相反, 在小冰期中国西南湿润, 北方千旱. 此外, 北宋末年靖 康事件(AD1127)后中国政治经济中心首次迁移到中国南方，改变了历史上中国人口北多南少的分布模式. 因此， 中世纪暖期中国西南干旱的气候和大量人口的迁入、战争、大规模开垦耕地以及大面积农作物的种植，加剧了 中国西南石漠化的扩张.

\footnotetext{
中文引用格式: 陈朝军, 袁道先, 程海, Yu T, Shen C, Edwards R L, 吴尧, 肖思雅, 张键, 王涛, 黄再, 刘子琦, 李廷勇, 李俊云. 2021. 人类活动和气候变化触发了 中国西南石漠化的扩张. 中国科学: 地球科学, 51(11): 1950-1963, doi: 10.1360/N072020-0242

英文引用格式: Chen C, Yuan D, Cheng H, Yu T, Shen C, Edwards R L, Wu Y, Xiao S, Zhang J, Wang T, Huang R, Liu Z, Li T, Li J. 2021. Human activity and climate change triggered the expansion of rocky desertification in the karst areas of Southwestern China. Science China Earth Sciences, 64(10): 1761-1773, https://doi.org/10.1007/s11430-020-9760-7
} 
关键词石漠化, 靖康事件, 石笋 $\delta^{13} \mathrm{C}$, 中世纪暖期, 小冰期

\section{1 引言}

石漠化是指喀斯特地区地表植被和土壤演变为几 乎没有植被和土壤的岩石景观(Yuan, 1997; 网络版附 图S1，http://earthen.scichina.com). 石漠化是中国以及 全球喀斯特地区最严峻的生态环境问题(Bai等，2011; Jiang等，2014). 尤其是中国西南地区喀斯特面积共 $7.5 \times 10^{5} \mathrm{~km}^{2}$ ，占总面积的 $43 \%$ (Zeng等，2016)，生态系 统脆弱、人地矛盾突出、水土流失和石漠化严重(图 1), 严重制约区域经济可持续发展(张甘霖等, 2019). 过 去几十年，虽然中国西南的石漠化得到了有效的控制， 但是因为全球变暖, 洪涝灾害更加频繁, 该区域面临着 再次石漠化, 甚至石漠化扩大的风险(Jiang等, 2014; 郭 纯青等, 2015). 而早在3000 4000年前, 人类活动的增 强(人口增长、农业种植扩张、战争)就已经改变了喀 斯特地区石漠化的自然过程(Gams，1991; Yassoglou, 2000；Liu等，2011)。在北宋末年(AD1127)，金人攻陷 北宋都城开封, 徽、钦二帝被掳, 北宋灭亡, 史称靖康 事件(代谦和别朝霞，2015). 靖康事件后，中国古文明 的政治和经济中心从北方向南迁移至长江以南的临安 府(杭州)(图1a). 继而中国人口大规模向南迁移(韦启 光, 1986; 吴松弟, 2000; 代谦和别朝霞, 2015), 也就改 变了生态环境的自然演化. 因此, 探究这一时期人类活 动和气候变化对石漠化的影响具有重要的意义.

洞穴石笋已经成为重建古气候和古环境变化的重 要地质载体(Wang等, 2001，2005; Fleitmann等, 2003; Yuan等, 2004; Wang等, 2017; 程海等, 2019). 石笋精确 的U-Th测年及其连续且高分辨率的记录，不仅仅为全 球古气候变化提供了参考(Wang等, 2001, 2005; Fleitmann等, 2003; Yuan等, 2004; Wang等, 2017; 程海等, 2019), 而且为气候变化导致的人类文明演变(如玛雅 文明、印度河文明、两河文明以及中国古文明)提供 了诸多的证据(Polyak和Asmerom, 2001; Zhang Q等, 2008; Kathayat等, 2017; Siha等, 2019). 然而, 这些研究 主要集中在石笋 $\delta^{18} \mathrm{O}$ 和石笋纹层的指标上, 而就石笋 $\delta^{13} \mathrm{C}$ 的关注很少. 石笋 $\delta^{13} \mathrm{C}$ 受控于洞穴外部气候因素 和非气候因素(Liu等，2016；Li等，2018；程珂等，
2019), 由于区域水文差异的影响，各记录内部细节表 现出差异(Tan等, 2015; Liu等, 2016; Li等, 2018). 但是 相对于石笋 $\delta^{18} \mathrm{O}, \delta^{13} \mathrm{C}$ 往往更加敏感地响应于洞穴外 部生态环境变化(Zhang等, 2015; Liu等, 2016). 本研究 利用中国西南区域洞穴石笋 $\delta^{13} \mathrm{C}$ 探究过去 2000 年以来 人类活动和气候变化对喀斯特地区石漠化的影响.

\section{2 研究区域和样品}

石将军洞 $\left(26.2^{\circ} \mathrm{N}, 105.5^{\circ} \mathrm{E}\right.$, 海拔 $\left.1300 \mathrm{~m}\right)$ 位于中国 西南贵州省安顺市(图1). 地处云贵高原东部的梯级状 斜坡地带, 地貌类型属于峰从洼地. 石将军洞发育于三 叠系中上统中厚层灰质白云岩(李洣等, 2016), 洞顶上 覆基岩厚度约 $100 \mathrm{~m}$ ，灌从植被发育。洞口高 $2 \mathrm{~m}$, 宽 $1.5 \mathrm{~m}$, 整个洞长约 $500 \mathrm{~m}$. 洞内空气与外界大气流动交 换甚少, 洞穴温度常年保持在 $15^{\circ} \mathrm{C}$ 左右(李渊等, 2016). 年平均降水量为 $1400 \mathrm{~mm}(\mathrm{Li}$ 等，2021). 该地区气候受 亚洲夏季风影响较大, 雨季水汽主要来自印度洋和太 平洋(图1).

本研究基于石将军洞的两根石笋(SJJ-300和SJJ7). SJJ7石笋整体呈圆柱状, 沉积连续, 生长轴有3次轻微 偏移, 沿其生长轴测得石笋总长约为 $254 \mathrm{~mm}$, 在距离顶 部30 19mm处生长有 $11 \mathrm{~mm}$ 的方解石沉积(图2a). SJJ300 石笋生长轴存在 6 次偏移, 按其生长轴测得石笋总 长为 $330 \mathrm{~mm}$ (图2b).

\section{3 方法}

在两个石笋(SJJ-300和SJJ7)的抛光剖面上, 使用 直径为 $1 \mathrm{~mm}$ 的牙钻, 平行于生长层钻取 10 50mg粉末, 进行U-Th年代测试. 在石笋SJJ7和SJJ-300分别钻取 47 和 55 个年代样品. 采样位置在图2中展示. 参照Edwards 等(1987)、Shen等(2012)和Cheng等(2013)的化学标准 流程分离U和Th. SJJ-300石笋的 ${ }^{230} \mathrm{Th}$ 年龄在台湾大学 高精度质谱与环境变化实验室完成. SJJ7石笋的 ${ }^{230} \mathrm{Th}$ 年龄其中 3 个在台湾大学高精度质谱与环境变化实验 室完成, 剩余 44 个在西安交通大学全球环境变化研究 

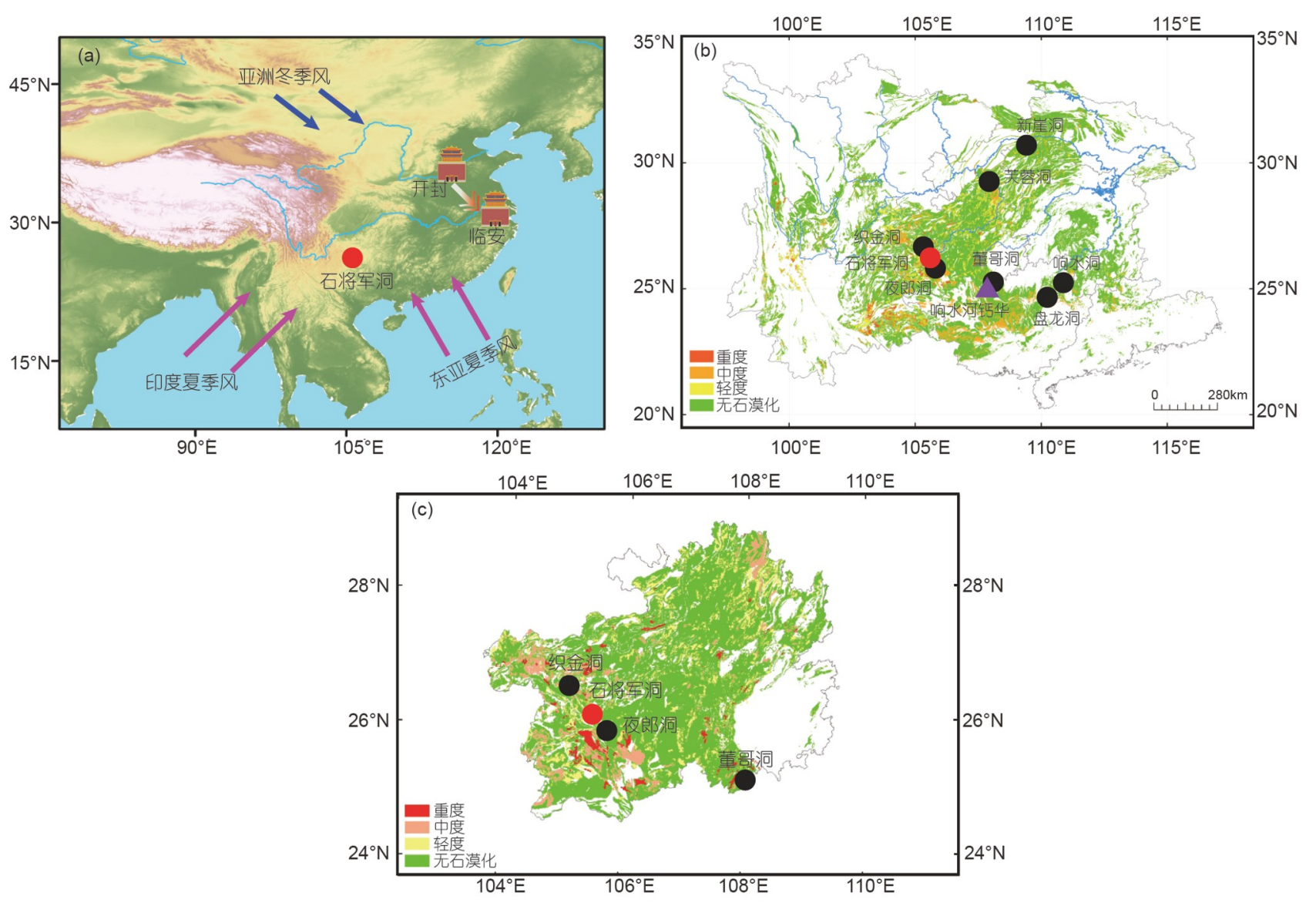

图 1 石将军洞和其他古气候记录的位置

(a) 石将军洞的位置和亚洲季风示意图. 紫色箭头代表印度夏季风和东亚夏季风, 蓝色箭头代表亚洲冬季风. 开封为北宋都城位置, 临安为南 宋都城位置, 靖康事件后, 宋朝都城从开封迁往临安. (b) 中国西南区域石漠化分布和等级. (c) 贵州省石漠化分布和等级. 红色点为石将军洞 (本研究), 黑色点为其他记录(表1)和盘龙洞(Yin等, 2019)的位置. 紫色三角形为响水河钻华位置(Liu等, 2011). 石漠化数据来自Li等(2008)和 Bai等(2011)

院同位素实验室完成. ${ }^{230} \mathrm{Th}$ 年龄测量利用Neptune型多 接受电感耦合等离子体质谱仪(MC-ICP-MS)完成, 年 龄误差为 $( \pm 2 \sigma)$ 统计误差. 衰变常数 ${ }^{230} \mathrm{Th}$ 采用 $9.1705 \times 10^{-6} \mathrm{a}^{-1}$ (Cheng等, 2013), ${ }^{234} \mathrm{U}$ 采用 $2.82206 \times 10^{-6} \mathrm{a}^{-1}$ (Cheng等，2013)， ${ }^{238} \mathrm{U}$ 采用 $1.55125 \times 10^{-10} \mathrm{a}^{-1}$ (Jaffey等，1971). 初始 ${ }^{230} \mathrm{Th}$ 年龄校正 采用地壳 ${ }^{230} \mathrm{Th} /{ }^{232} \mathrm{Th}$ 平均比值为 $(4.4 \pm 2.2) \times 10^{-6}$. 这些是 物质在长期平衡状态下的值, 地球 ${ }^{232} \mathrm{Th} /{ }^{238} \mathrm{U}$ 值为 3.8 . 在抛光后的石笋剖面上，采用直径为 $0.5 \mathrm{~mm}$ 的牙钻沿 石笋生长中心轴(图2), 每间隔 $0.25 \mathrm{~mm}$ 取一个同位素 样品. 石笋 $\delta^{13} \mathrm{C}$ 在西南大学地球化学与同位素实验室 采用Delta-V-Plus型质谱与碳酸盐自动进样装置Kiel IV联机测试，每7个样品插入一个标准样品(SWU-1);
结果以Vienna-Pee Dee Belemnite standard (V-PDB)标 准给出, 分析误差 $( \pm 1 \sigma)$ 对 $\delta^{13} \mathrm{C}$ 小于 $0.06 \%$ ( $\mathrm{Li} \mathrm{T} \mathrm{Y}$ 等, 2011).

\section{4 结果}

${ }^{230} \mathrm{Th}$ 的测年结果如网络版附表S1所示, SJJ-300和 SJJ7石笋的 ${ }^{238} \mathrm{U}$ 浓度的变化范围分别为8031 50743和 $385 \sim 7542 \mathrm{ppb}\left(1 \mathrm{ppb}=1 \mu \mathrm{g} \mathrm{kg}{ }^{-1}\right)$, 两个石笋的年代样品 测年误差分别小于 6 和 $59 \mathrm{a}$ ，平均测年误差分别为 \pm 3.4 和 $\pm 14.1 \mathrm{a}$. 在Mod-Age软件中利用测年结果建立两个 石笋的年代(Hercman和Pawlak，2012)，模拟结果表明 SJJ7生长于BC1158 AD1256(图2c). SJJ-300石笋生长 

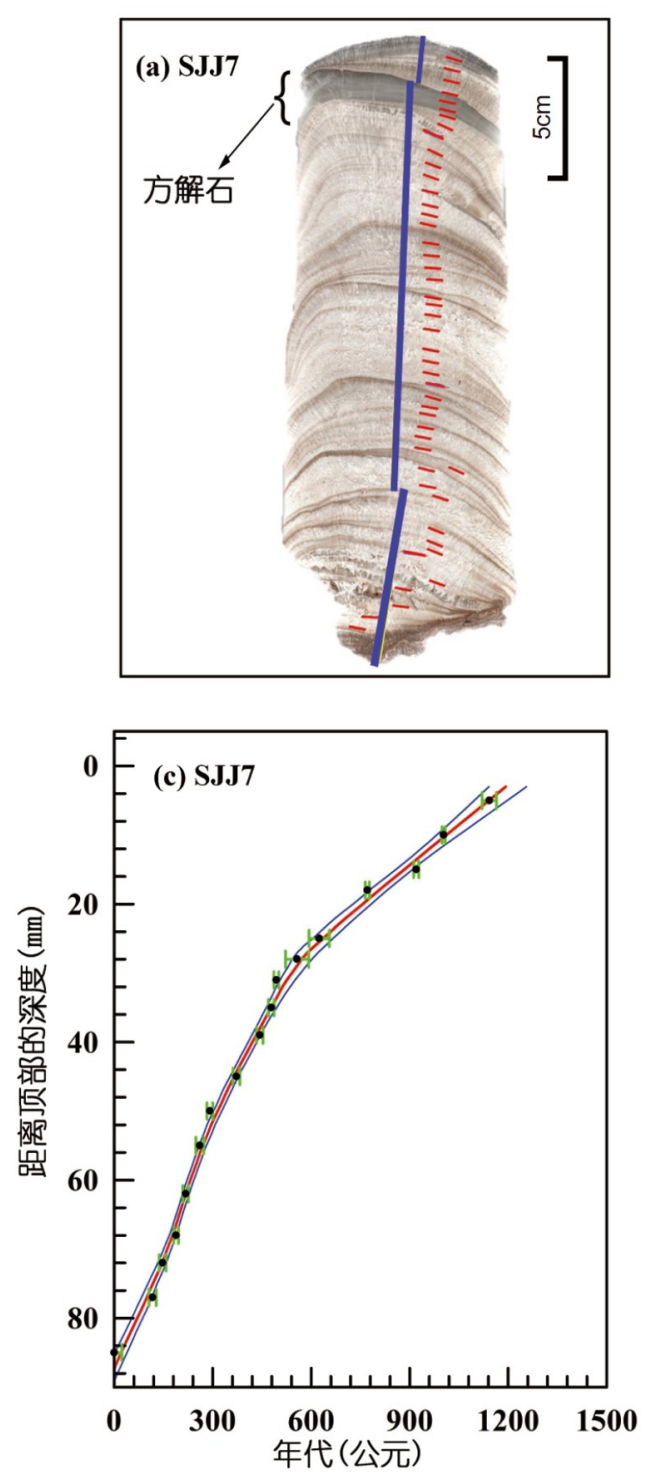
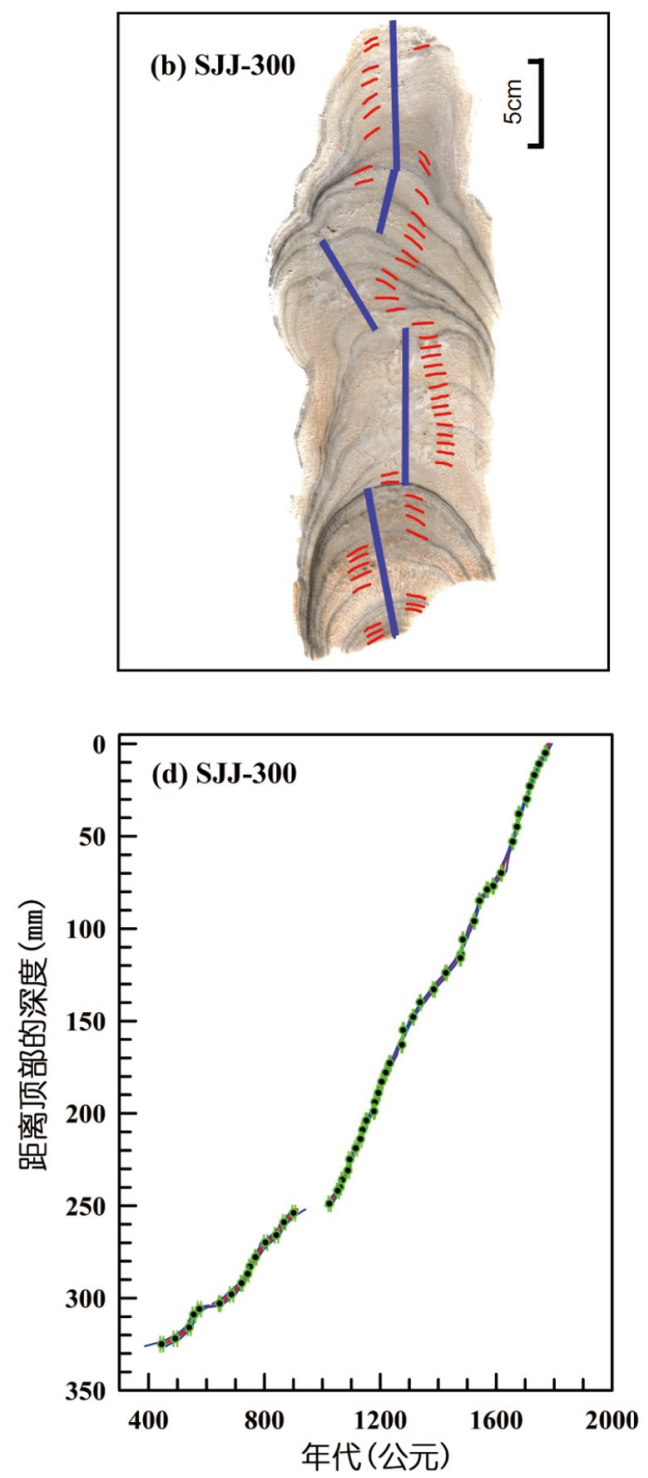

图 2 SJJ7和SJJ-300石笋样品和年代模型

(a)和(b)分别为SJJ7和SJJ-300石笋剖面图, 蓝色实线为氧碳同位素采样路径, 红色短横线为年龄采样位置; (c) 和(d)是利用Mod-Age软件分别模 拟SJJ7和SJJ-300石笋的年代模型(Hercman和Pawlak, 2012)

于AD380 1782，但在AD578 631(305.25 mm处)和 AD924 1023(250mm处)期间存在2个沉积间断(图2d).

同一生长阶段SJJ7和SJJ-300石笋 $\delta^{13} \mathrm{C}$ 变化趋势相 似(图3a), 显著相关 $(R=0.31, p \leq 0.01)$, 分辨率分别达到 3.6 和1a. 同一母液在沉积为文石和方解石矿物时碳同 位素分馏系数不同, 方解石中的 $\delta^{13} \mathrm{C}$ 相对于文石偏轻 (Tarutani等, 1969; Scroxton等, 2017). 参考Fohlmeister 等(2018)的研究, 本研究将SJJ7石笋方解石段的 $\delta^{13} \mathrm{C}$ 校
正 $(1.07 \pm 0.41) \%$, 校正后的 $\delta^{13} \mathrm{C}$ 记录没有改变整条记录 的变化趋势(网络版附图S2). SJJ7石笋 $\delta^{13} \mathrm{C}$ 校正后变化 范围为 $-6.1 \sim 1.1 \%$, 平均值为 $-3.8 \%$, 从中世纪暖期到 小冰期整体偏重 $5.9 \%$. 在AD0 1127, SJJ7石笋 $\delta^{13} \mathrm{C}$ 的 平均值为 $-4.0 \%$; 在 $\mathrm{AD} 1128 \sim 1256$, 平均值为 $-0.4 \%$. $\mathrm{SJJ}-300$ 石笋 $\delta^{13} \mathrm{C}$ 变化范围为-8.1 -1.6\%. 从中世纪暖 期到小冰期偏重 $6.5 \%$; 在AD380 1125, 平均值为 $-5.5 \%$; 在AD1127 1782, 平均值为 $-4.3 \%$. SJJ-300和 


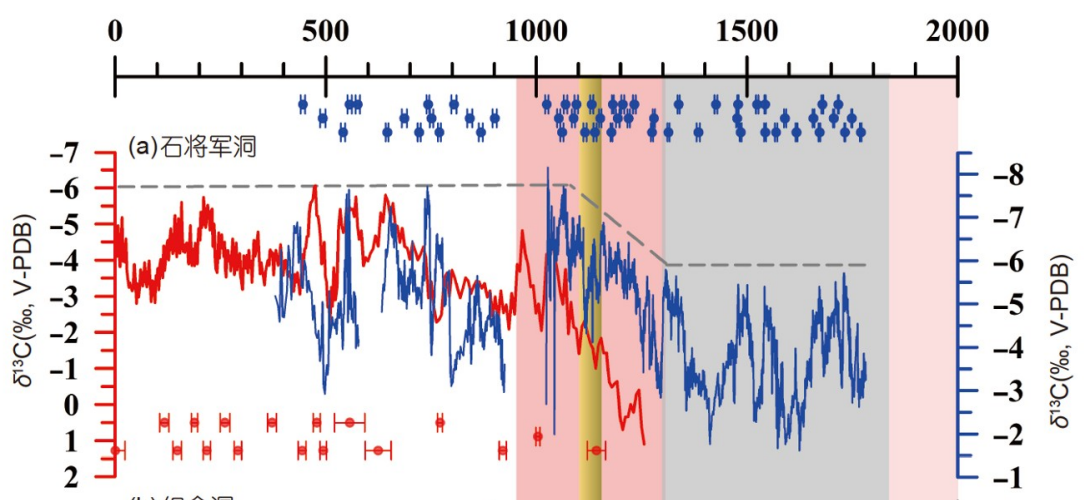

(b) 织金洞

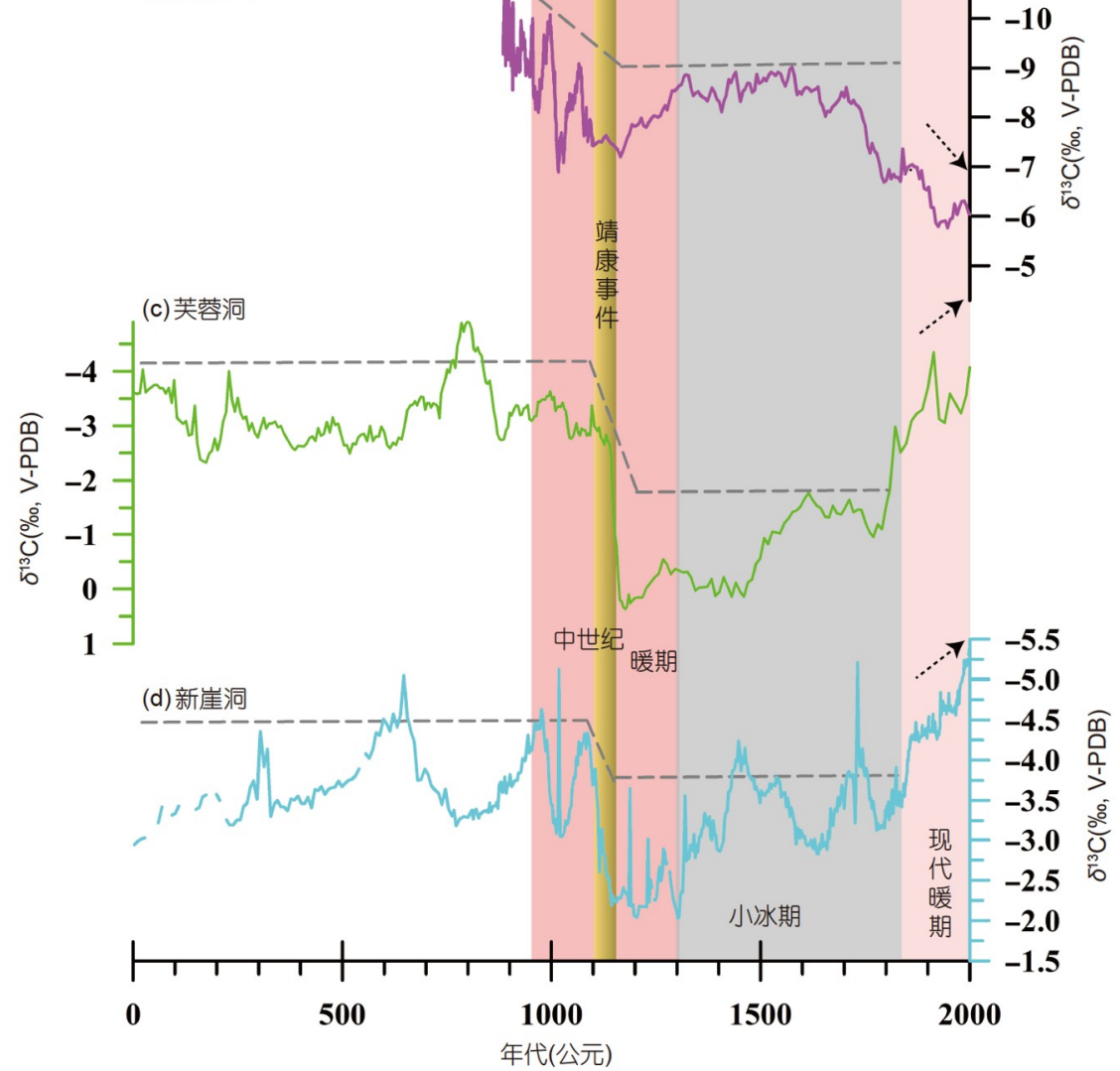

图 3 过去 2000年SJJ7和SJJ-300石笋 $\boldsymbol{\delta}^{13} \mathrm{C}$ 及中国西南区域石笋 $\delta^{13} \mathrm{C}$ 变化

(a) $\mathrm{SJJ} 7$ (红色曲线)和SJJ-300(蓝色曲线)石笋 $\delta^{13} \mathrm{C}$ 记录, 红色和蓝色误差棒分别为 SJJ7和SJJ-300石笋测年点和测年误差; (b) 织金洞石笋 $\delta^{13} \mathrm{C}$ 记 录(Kuo等, 2011); (c) 芙蓉洞石笋 $\delta^{13} \mathrm{C}$ 记录 (Li H C 等, 2011); (d) 新崖洞石笋 $\delta^{13} \mathrm{C}$ 记录 (Li等, 2017). 粉红色条带分别代表中世纪暖期和现代暖期, 灰色条带代表小冰期. 灰色虚线表示各个记录的变化趋势, 黑色虚线箭头表示现代暖期不同记录的变化

$\mathrm{SJJ} 7$ 石笋的 $\delta^{13} \mathrm{C}$ 值存在差异，这可能是由于上覆基岩 厚度、土壤厚度、植被、滴速和同一洞穴不同滴水点 滞留时间的差异造成的(Li和Li, 2018; Li等, 2018). 然 而，靖康事件后两个石笋 $\delta^{13} \mathrm{C}$ 都显著偏重(图3a). 同一 洞穴两个石笋 $\delta^{13} \mathrm{C}$ 的一致的变化，至少反映了共同的 驱动机制(Liu等, 2016).

\section{5 讨论}

\section{1 石笋 $\delta^{13} \mathbf{C}$ 可以指示石漠化的演变}

上覆土壤 $\mathrm{CO}_{2}$ 和洞穴碳酸盐围岩是石笋中碳的两 个主要来源(Bergel等, 2017; 程珂等, 2019). 洞穴的通 风性、基岩的溶解程度、植被类型和密度、土壤中微 
生物活性、岩溶表层带方解石的先期沉积 $(\mathrm{PCP})$ 、滴 水的蒸发和脱气都会影响石笋 $\delta^{13} \mathrm{C}$ 的变化(Fairchild等, 2006; Tan等, 2015; Li等, 2018). 这些影响因子均受控 于区域内洞穴水文环境的影响(Li等, 2018), 往往会导 致不同区域中洞穴石笋 $\delta^{13} \mathrm{C}$ 的空间差异(Liu等，2016). 但是大区域的石笋 $\delta^{13} \mathrm{C}$ 与气候因子(降水量和温度) 密 切相关(Li T Y 等, 2011, 2018), 而气候变化将会导致大 区域内水文环境存在共性, 因此, 大区域内不同洞穴中 石笋 $\delta^{13} \mathrm{C}$ 具有相似的环境意义.

石笋 $\delta^{13} \mathrm{C}$ 也可能反映的是植被覆盖度的变化, 在 湿润的气候条件下, 植被覆盖较多时 $\delta^{13} \mathrm{C}$ 偏轻, 植被覆 盖较少时 $\delta^{13} \mathrm{C}$ 偏重( $\mathrm{Li}$ 等, 2017). 土壤中植物的呼吸作 用和微生物活动产生的 $\mathrm{CO}_{2}$ 可能是影响石笋 $\delta^{13} \mathrm{C}$ 的主 要因素(Bergel等, 2017; Li等, 2018). 在干冷季节, 植被 生长速率被限制, 源于微生物的土壤 $\mathrm{CO}_{2}$ 产率减少, 滴 水滴速减缓, 滴水的 $\mathrm{CO}_{2}$ 脱气作用增强, 石笋中 $\delta^{13} \mathrm{C}$ 偏 重(Zhao等, 2015, 2017). 现代监测结果表明滴水中 $\delta^{13} \mathrm{C}$ 受控于地表降水和温度以及土壤中的 $\mathrm{CO}_{2}$ ：冬春季节 $\delta^{13} \mathrm{C}$ 偏高, 夏秋季节偏低( $\mathrm{Li}$ 和 Li, 2018).

气候变化和人类活动(人口迁移、农业生产、森 林的砍伐等)会导致地表植被的破坏和土壤生产力的 退化, 进而引发石漠化(Li等, 2018; 王世杰等, 2020). 石 漠化扩张, 地表植被覆盖度降低, 土壤厚度变薄, 土壤 中植物呼吸作用和微生物活动产生的土壤 $\mathrm{CO}_{2}$ 浓度降

(a)

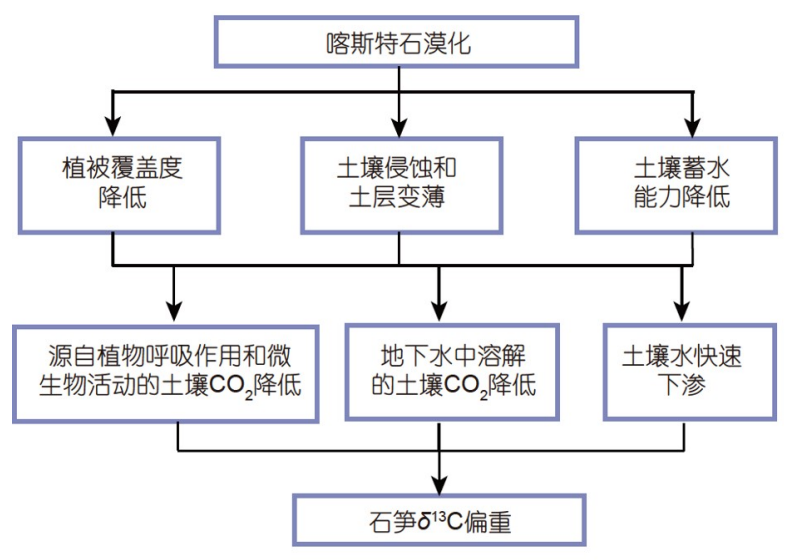

低( $\mathrm{Li}$ 和 $\mathrm{Li}, 2018 ; \mathrm{Li}$ 等, 2018). 此外, 土壤蓄水能力下降, 入渗速度加快, 更少的土壤 $\mathrm{CO}_{2}$ 溶入地下水 $(\mathrm{Li}$ 和 $\mathrm{Li}$, 2018). 以上因素均可导致石笋的 $\delta^{13} \mathrm{C}$ 值偏重(图4a). 另 外, 自AD1984以来中国接连颁布相关法律(《中华人 民共和国森林法》 《中华人民共和国草原法》 《中华 人民共和国水土保持法》)和措施(退耕还林生态工 程、还林还草生态工程)来保护生态环境(王世杰等, 2020; 罗旭玲等, 2021). 中国西南部的石漠化得到了有 效的控制和恢复(罗旭玲等, 2021). 贵州盘龙洞和重庆 新崖洞石笋 $\delta^{13} \mathrm{C}$ 表明: 在AD1970 2009期间, 随着喀斯 特地区生态环境恢复, 石笋 $\delta^{13} \mathrm{C}$ 逐渐偏轻(图4b)( $\mathrm{Li}$ 等, 2017; Yin等, 2019). 因此, 在喀斯特地区石笋 $\delta^{13} \mathrm{C}$ 可以 指示石漠化的演变(Zhang等, 2004; Liu等, 2011; Li等, 2018; Yin等, 2019).

\section{2 靖康事件后中国西南区域石漠化扩张加剧}

靖康事件后, SJJ7和SJJ-300石笋 $\delta^{13} \mathrm{C}$ 逐渐偏重, 并 且在整个小冰期持续偏重(图3a). 在同一区域(图1)的 织金洞石笋 $\delta^{13} \mathrm{C}$ 同样在靖康事件后显著偏重(图2b). 在 $\mathrm{AD} 1100$ 后，重庆芙蓉洞石笋 $\delta^{13} \mathrm{C}$ 从- $2.6 \%$ 迅速偏重到 $-0.9 \%$ ( $\mathrm{Li} \mathrm{H} \mathrm{C}$ 等, 2011). 同一时期, 重庆新崖洞石笋 $\delta^{13} \mathrm{C}$ 也显著偏正，甚至比后期的小冰期时的 $\delta^{13} \mathrm{C}$ 更加 偏重(图3d; Li等, 2017). 而且, 贵州响水洞石笋 $\delta^{13} \mathrm{C}$, 在AD1100偏正的幅度要远远超过过去6000年的变化

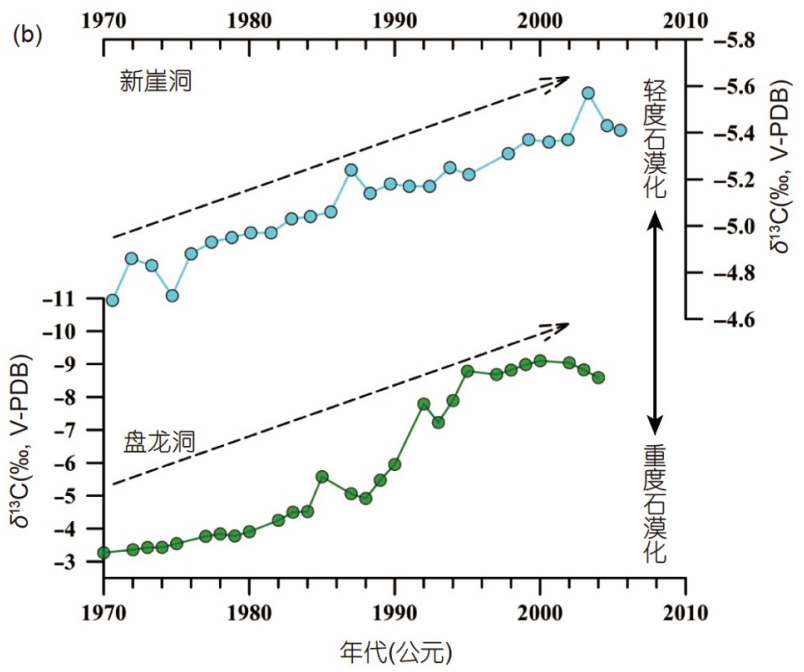

图 4 石漠化与石笋 $\delta^{13} \mathrm{C}$ 之间的关系

(a) 石漠化与石笋 $\delta^{13} \mathrm{C}$ 之间的概念模型; (b) 自 $\mathrm{AD} 1980$ 石漠化恢复以来, 新崖洞石笋( $\mathrm{Li}$ 等, 2017)和盘龙洞石笋 $\delta^{13} \mathrm{C}$ 记录(Yin等, 2019)逐渐偏轻 的变化 
(Zhang等, 2004). 与此同时, 同一区域的夜郎洞和董哥 洞石笋 $\delta^{13} \mathrm{C}$ 甚至达到了Younger Dryas事件和Heinrich 事件的偏正幅度(表1)(Kuo等, 2011; Liu等, 2016; Zhao 等, 2017). 此外, 贵州响水河钲华研究表明在AD1270 左右, 钲华 $\delta^{13} \mathrm{C}$ 也呈现出阶梯式突变(Liu等, 2011). 因 此, 在 $\mathrm{AD} 1100$ 年后, 石笋 $\delta^{13} \mathrm{C}$ 的显著偏正并不仅仅是 单个洞穴中的现象, 而是西南喀斯特地区共同的特征 (表1). 夏季风减弱(Liu等, 2016)、人口迁入引起的大 规模森林砍伐(Zhao等, 2015)、植被覆盖度减小(Li等, 2017)、农业活动增强(Zhang等，2004)、C4农作物的 引入(Liu等, 2011)等, 被用来解释各记录中的这一突 变. 虽然这些解释各自基于单一的记录, 但是可能指 示了这一时期西南喀斯特地区人类活动的增强和石漠 化的快速扩张. 而这些石笋 $\delta^{13} \mathrm{C}$ 记录存在的差异(图3), 可能反映了靖康事件后不同强度的人类活动造成了不 同的石漠化水平.

\section{3 中世纪暖期和小冰期亚洲季风区降水模式}

大量的古气候重建记录也表明过去2000年中国气 候变化存在两个百年尺度的异常期: 中世纪暖期和小 冰期(Wang等, 2005; Zhang P Z等, 2008; Chen等, 2015; Zhao等，2020). 尽管关于中世纪暖期和小冰期 的起止时间仍然略有争议, 但是大量的记录表明, 在 AD950 1300和AD1300 1850期间亚洲夏季风(东亚夏
季风和印度夏季风)存在显著的转变(网络版附表 S2), 而中国夏季风区西南区域与中国北方表现出相反变化 的模式(图5). 通过对石笋、湖泊、泥炭、花粉、黄 土、历史资料等多个地质载体和多指标记录的古气候 信息综合对比(网络版附表S2), 结果表明受东亚夏季 风的影响, 在中世纪暖期中国西南地区气候偏干, 北 部和东部区域气候湿润(图5a), 印度夏季风区北部湿 润(图 5a). 小冰期时期中国西南地区气候湿润, 华北和 东北地区气候偏干(图5b); 印度季风区北部干旱(图 $5 b$ ), 与其他古气候集成研究以及古气候模拟研究结果 相似(网络版附表S3). 古气候模拟也表明在中世纪暖 期, 印度夏季风北移, 北部湿润, 中部异常干旱; 小冰 期印度夏季风减弱(Polanski等, 2014).

在中世纪暖期(小冰期), 北半球温度增加(降低), 半球间温度梯度增加(减小), 导致东亚夏季风和印度 夏季风加强(减弱), 雨带向北(南)移动(Liu等, 2014), 使得东亚季风区北部地区以及印度季风区北部降水增 加(减少)(Zhao等, 2020). 此外, 中世纪暖期强的El Niño 事件会导致低纬度热带太平洋Walker环流西上升支向 东移动，导致中国季风区南部降水减少(Yan等，2011; Tan等, 2019; Duan等, 2020). 同时El Niño促进极端印 度洋偶极子(IOD)正相位的发展; 在IOD正相位时, 东 印度洋海温降低, 受下沉气流的影响, 东印度洋周边的 东南亚地区降水减少(Abram等, 2020).

表 1 中世纪暖期到小冰期中国西南部石笋和钙华 $\delta^{13} \mathrm{C}$ 增加幅度

\begin{tabular}{|c|c|c|c|c|c|c|c|}
\hline 站点 & 缩写 & 位置 & $\begin{array}{c}\text { 持续时间 } \\
\text { (公元) }\end{array}$ & 指标 & 增加幅度 & 影响因子 & 参考文献 \\
\hline 石将军洞 & SJJ & $\begin{array}{c}26.20^{\circ} \mathrm{N}, 105.50^{\circ} \mathrm{E} \\
1300 \mathrm{~m}\end{array}$ & 950 1350年 & 石笋 & $5.9 \%$ 和 $6.5 \%$ & 气候变化和人类活动 & 本研究 \\
\hline 新崖洞 & $\mathrm{XY}$ & $\begin{array}{c}30.75^{\circ} \mathrm{N}, 109.47^{\circ} \mathrm{E} \\
1250 \mathrm{~m}\end{array}$ & 1000 1400年 & 石笋 & $2.5 \%$ & $\begin{array}{c}\text { 植被覆盖度的降低和 } \\
\text { 人类活动的增加 }\end{array}$ & $\mathrm{Li}$ 等, 2017 \\
\hline 芙蓉洞 & FR & $\begin{array}{c}29.23^{\circ} \mathrm{N}, 107.90^{\circ} \mathrm{E} \\
480 \mathrm{~m}\end{array}$ & 1150 1500年 & 石笋 & $4.4 \%$ & 没有讨论 & Li等, 2011 \\
\hline 夜郎洞 & YL & $\begin{array}{c}26.04^{\circ} \mathrm{N}, 105.74^{\circ} \mathrm{E} \\
1285 \mathrm{~m}\end{array}$ & 1300 1900年 & 石笋 & $8.0 \%$ & $\mathrm{C} 4$ 植物和人类活动的增加 & Zhao等, 2017 \\
\hline 织金洞 & ZJ & $\begin{array}{c}26.35^{\circ} \mathrm{N}, 105.33^{\circ} \mathrm{E} \\
1300 \mathrm{~m}\end{array}$ & 990 1800年 & 石笋 & $3.3 \%$ & 森林砍伐和人口迁移 & Kuo等, 2011 \\
\hline 响水洞 & $\mathrm{XSC}$ & $\begin{array}{c}25.48^{\circ} \mathrm{N}, 111.88^{\circ} \mathrm{E} \\
400 \mathrm{~m}\end{array}$ & 1000 1500年 & 石笋 & $7.0 \%$ & $\mathrm{C} 4$ 植物和人类活动的增加 & Zhang等, 2004 \\
\hline 响水河钙化 & XSR & $\begin{array}{c}25.47^{\circ} \mathrm{N}, 107.88^{\circ} \mathrm{E} \\
700 \mathrm{~m}\end{array}$ & 1000 1270年 & 钻华 & $1.9 \%$ & C4农作物的引入 & Liu等, 2011 \\
\hline 董哥洞 & DG & $\begin{array}{c}25.28^{\circ} \mathrm{N}, 108.08^{\circ} \mathrm{E} \\
680 \mathrm{~m}\end{array}$ & 1000 1400年 & 石笋 & $1.6 \%$ & 弱夏季风 & Liu等, 2016 \\
\hline
\end{tabular}



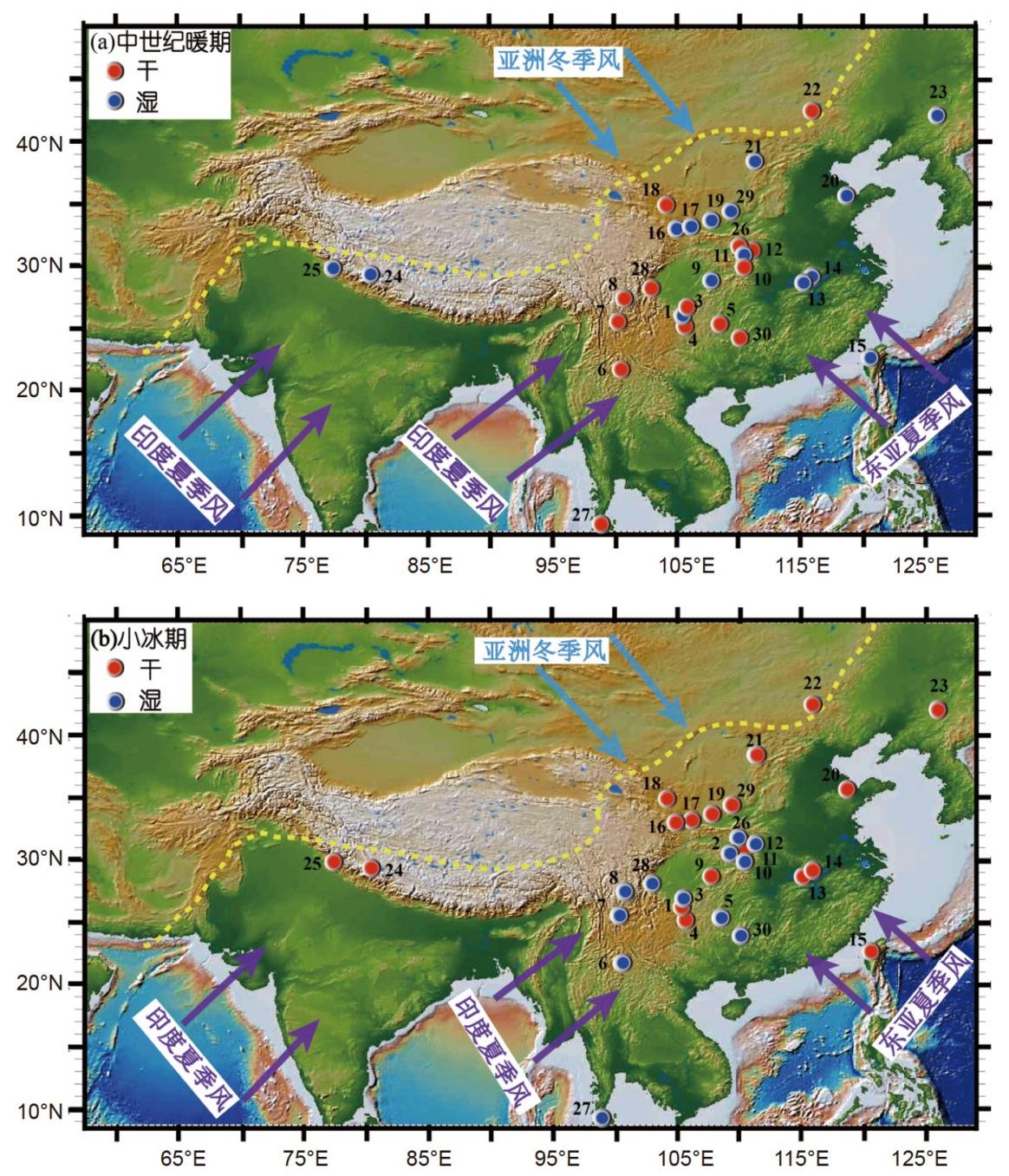

图 5 亚洲季风区气候变化

(a) 中世纪暖期亚洲季风区干湿模式; (b) 小冰期亚洲季风区干湿模式. 红色圆点代表干旱, 蓝色圆点代表湿润. 各记录信息见网络版附表S2, 紫色箭头代表印度夏季风和东亚夏季风, 蓝色箭头代表亚洲冬季风. 黄色虚线代表现代亚洲夏季风边界(Sun等, 2019)

历史文献记录表明, 在过去2000年中, 中国的旱涝 格局在不同的冷暖气候背景下呈现不同的分布规律 (郑景云等，2014). 在温暖的 AD 1000 1100和 AD1190 1290时期，中国西南地区长期干旱，而东部 地区长期湿润(郑景云等，2014)。AD1126左右中国平 均气温显著偏低, $\mathrm{AD} 1111$ 太湖全部封冻, 冰上可通行 车辆, 当年福州荔枝全部冻死(张善余，1991). 至 AD1329 1353, 太湖又有两次封冻, “冰厚数尺，人履 冰上如平地，洞庭柑橘冻死几尽”(张善余，1991). AD1483 1513, 太湖、鄱阳湖、洞庭湖都出现封冻现 象, 长江流域的河湖水面冬季多次结冰(张善余,
1991). 然而长江流域夏季洪涝灾害频发(Zhang Q等, 2008). 这些历史记载都证明这一时期气候发生了突变 事件.

北半球和中国的温度记录表明中世纪暖期并不是 一个稳定的温暖期, 但小冰期温度显著偏低(图6a)(Kobashi等, 2012). 在AD1100后, 中国温度突然降低, 之后 经历了一个约70年短暂的温暖期后进入小冰期(图6b) (Ge等, 2013). 在中世纪暖期, 中国西南部降水减少, 洞 穴上部裂隙管道开放, 渗透水下渗时间延长, PCP作用 和 $\mathrm{CO}_{2}$ 脱气加强( Tan等, 2015; Liu等, 2016; Li等, 2018), 导致石将军洞石笋 $\delta^{13} \mathrm{C}$ 在 $\mathrm{AD} 1100$ 后逐渐偏重(图6c). 

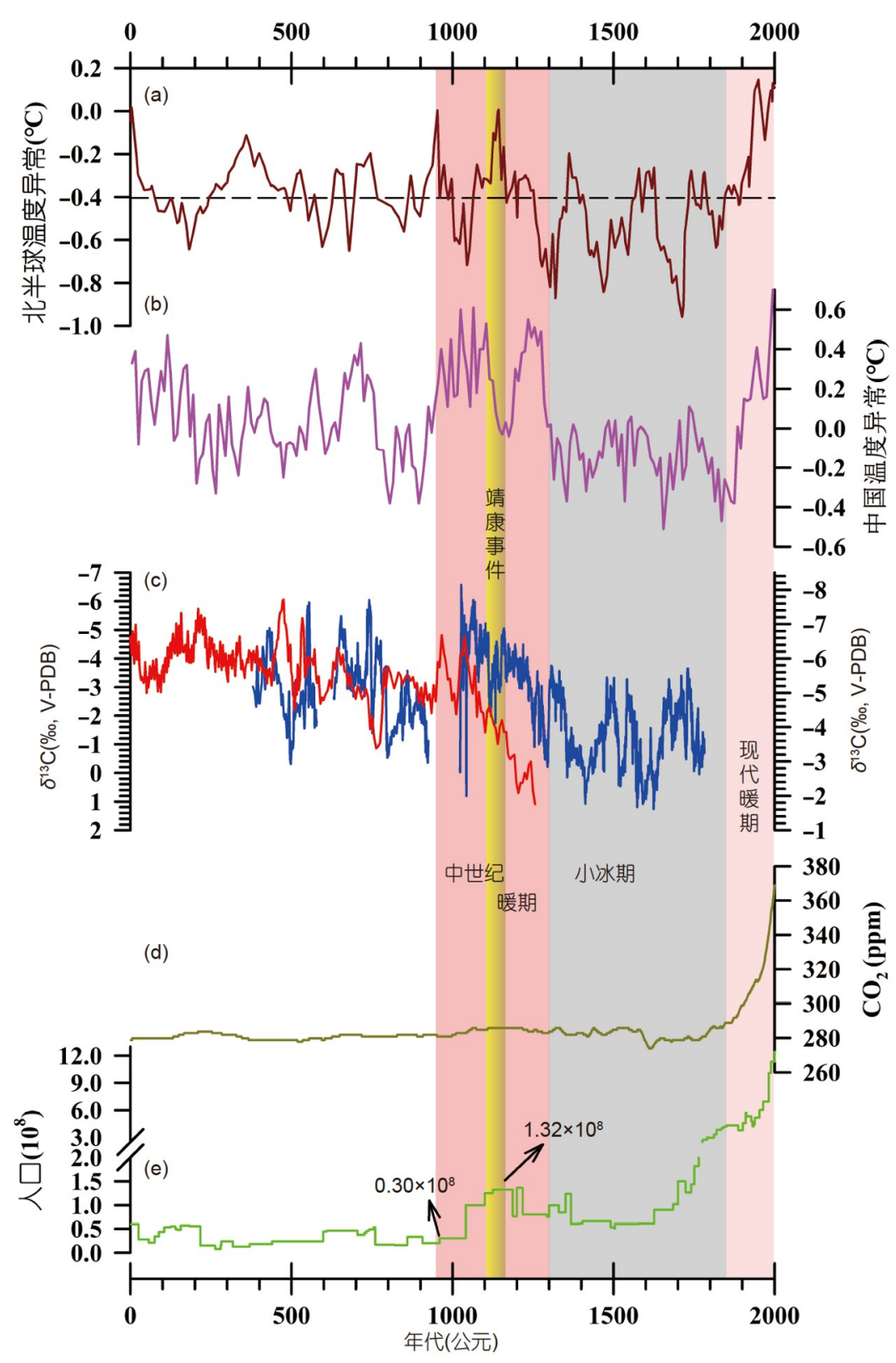

图 6 靖康事件后中国西南石漠化扩张的原因

(a) 北半球温度异常变化(Kobashi等, 2012); (b) 中国温度异常变化 (Ge等, 2013); (c) SJJ7(红色曲线)和SJJ-300(蓝色曲线)石笋 $\delta^{13} \mathrm{C}$; (d) 大气 $\mathrm{CO}_{2}$ 浓度变化(Etheridge等，1996)；(e) 中国历史人口变化(赵文林，1988). 粉红色条带分别代表中世纪暖期和现代暖期，灰色条带代表小冰期. $1 \mathrm{ppm}=1 \mu \mathrm{L} \mathrm{L}^{-1}$

虽然小冰期时中国西南区域转变为湿润的气候条件 (图5b)，但是SJJ-300石笋 $\delta^{13} \mathrm{C}$ 持续偏重(图6c)，且中国 西南区域石笋和钙华的 $\delta^{13} \mathrm{C}$ 记录都同时偏重(表1)，从 中世纪暖期到小冰期，大气 $\mathrm{CO}_{2}$ 浓度没有发生显著的 转变(图6d). 但是AD1125时中国总人口为AD960时的 4.4 倍(图6e), 因此增强的人类活动可能引起了中国西
南部生态环境的显著变化.

\section{4 人类活动与石漠化扩张的关系}

多项研究表明, 在中国历史上, 人口大迁徙、经济 波动、战乱乃至朝代的更替等社会事件与气候变化存 在密切关系(Zhang P Z等, 2008; 方修琦等, 2015). 两宋 
时期人口迅速增长(赵文林，1988), 北宋时期中国人口 突破1亿，同时中国西南地区人口也快速增加(赵文林, 1988; 杨子慧, 1995; 吴松弟, 2000; 张世友和彭福荣, 2012). 在AD1100, 粮食减产, 饥荒指数增加, 北方游牧 民族南移(方修琦等, 2015; Lan等, 2020). 靖康事件期 间( AD1127), 中国南北方连续多年遭受战火, 致使总 人口锐减，大约 500 万北方移民迁入南方各地(吴松弟, 2000, 2001; 张世友和彭福荣, 2012). 战事平息后, 在 $\mathrm{AD} 1078$ 1162, 中国西南地区成为宋朝人口增长最快 的区域之一(吴松弟，2000). 宋朝嘉熙元年(AD1237), 元军大规模攻打四川，长达 50 年之久，战争导致 140 万 人死亡(吴松弟, 2000). 元朝中统年间(AD1260 1264), 中国西南部陷入战争(蓝勇, 1997). 中国西南乌江流域 有大批军事移民迁入, 在AD1127 1162, 广泛修建军事 防线, 展开了抗金反蒙的战争(张世友和彭福荣, 2012). 明朝洪武二十六年至弘治四年(AD1393 1491)，四川 人口由 140 多万增加到 260 多万(郭声波, 1988). 洪武年 末至万历初年(AD1398 1573), 总耕地面积由 11.5 万平 方千米增加到20.5万平方千米(郭声波，1988). 自宋代 开始，山西、江西、湖南及四川等地的人口不断移入 贵州, 使得贵州人口迅速增长(韦启光，1986; 李北构， 1990)。从唐朝天宝元年(AD742)到乾隆三十三年 (AD1768), 贵州登记人口从约16万人增加到 344.16 万 人(韦启光, 1986; 李北构, 1990). 此外, 靖康事件后北 方战争失利, 宋朝政府开始注重中国西南经济建设(董 春林，2015). 政府主要通过发展茶、盐、马匹交易以 及开采矿产来促进西南经济的发展(梁中效, 2004). 然 而, 由于经济发展与当地文化的冲突, 中国西南地区叛 乱频发(张文, 2004). 例如: 由于中国西南地区的少数 民族大多生活在山区，外来迁入人口砍伐了大量的树 木，修建大量的道路，使少数民族失去了他们的自然 屏障，从而引发了冲突(张文，2004)。在宋隆兴二年 (AD1164), 政府为缓解少数民族与政府之间的矛盾, 颁布了提供养牛、推广牛耕技术等相关措施(张文, 2002).

此外, 相较于 $\mathrm{AD} 0 \sim 1000$ 时期, 中国总人口从中世 纪暖期后期至小冰期, 呈现出阶梯式增加(图6e). 第一, 宋元时期的人口迁移改变了中国有史以来人口分布 “北多南少”的状况，使得人口重心向南迁移(杨子慧， 1995; 蓝勇, 1997). 第二, 中国西南人口快速增长, 大 规模迁入的人口不仅仅为该地区带来了先进的生产技
术，而且也需要开垦大量的土地以满足人口增长的需 要(张世友和彭福荣, 2012; 方修琦等, 2015). 第三, 大 面积的森林被砍伐(Kuo等, 2011), C4农作物快速代替 原生的C3 植物(李廷勇等, 2012; Li等, 2018). 因此, 宋 元时期中国西南喀斯特地区生态环境受到严重人为破 坏. 靖康事件后石漠化的扩张, 被持续偏重的石笋 $\delta^{13} \mathrm{C}$ 所记录(图3和图6).

工业革命以来，全球变暖和化石燃料的大量使用 导致大气 $\mathrm{CO}_{2}$ 浓度快速增高(图6d), 可能导致了现代暖 期中芙蓉洞和新崖洞石笋的 $\delta^{13} \mathrm{C}$ 偏轻(图 $3 \mathrm{c}$ 和 $\left.3 \mathrm{~d}\right)(\mathrm{Li} \mathrm{H}$ C等, 2011; $\mathrm{Li}$ 等, 2017). 然而, 织金洞石笋 $\delta^{13} \mathrm{C}$ 在现代 暖期中持续偏重(图3b). 与重庆芙蓉洞和新崖洞区域 相比，贵州织金洞区域属于严重石漠化地区(图1). 因 此, 重庆地区石漠化的恢复可能是芙蓉洞和新崖洞石 笋 $\delta^{13} \mathrm{C}$ 偏轻的主要原因, 而贵州地区持续的石漠化可 能导致了织金洞石笋 $\delta^{13} \mathrm{C}$ 偏重.

值得一提的是，关于小冰期时中国南北方和东亚 夏季风主控区域以及西风区的干湿变化, 仍然是一个 值得研究的问题(Li等, 2021). 由于当前对于东亚夏季 风区石笋 $\delta^{18} \mathrm{O}$ 变化主要影响因素的不确定性(Ruan等, 2019; Liu等, 2020; Li等, 2021), 单一利用石笋 $\delta^{18} \mathrm{O}$ 以及 其他低分辨率的记录来判断区域干湿变化存在一定的 不确定性(Zhang等，2018). 虽然在年际到年代际尺度 上, 大气降水中 $\delta^{18} \mathrm{O}$ 被环流强度、水汽源地、水汽输 送通道等影响, 但是, 在百年尺度上石笋 $\delta^{18} \mathrm{O}$ 被认为可 以反映干湿变化(Tan等, 2015, 2018; Yin等, 2019). 此 外, 多指标的研究将有助于精确地重建区域水文环境. 然而, 不论小冰期时中国西南地区的降水量是增加或 者减少, 本研究中贵州石将军洞石笋 $\delta^{13} \mathrm{C}$ 在靖康事件 时的突然转变(偏重)是非常清晰的(图3a), 并且织金 洞、芙蓉洞和新崖洞石笋 $\delta^{13} \mathrm{C}$ 均记录了这一变化(图 3b 3d) (Kuo等, 2011; Li H C等, 2011; Li等, 2017), 而且 该突变发生在小冰期之前，一直持续到AD1700左右 (图3). 这说明无论该时段夏季风或区域降水如何变化, 人类活动加剧(图6e)导致地表植被量的减少，与石笋 $\delta^{13} \mathrm{C}$ 突然偏重之间的关系是十分明确的.

\section{6 结论}

本研究利用高精度测年的石笋 $\delta^{13} \mathrm{C}$ 记录, 探讨了 中国西南喀斯特地区过去2000年来气候变化和人类活 
动对生态环境演化的影响. 通过古气候重建记录的综 合对比，表明中国西南区域与中国北方水文环境表现 出相反变化的模式. 中世纪暖期中国西南区域干旱的 气候条件诱发了生态环境的恶化，而靖康事件后 (AD1127)中国北方人口大规模南迁，大规模的森林砍 伐和耕地开垦等人类活动加剧了中国西南石漠化的扩 张. 因此, 气候变化和人类活动可能共同作用, 最终导 致中世纪暖期到小冰期期间中国西南喀斯特地区石漠 化的扩张. 在现代暖期, 重庆地区的石漠化逐渐恢复, 而贵州地区表现出了持续的石漠化. 尽管本研究的重 建结果基于有限的记录, 在未来的研究中需要更多高 分辨率的多指标综合记录来评估西南石漠化扩展的原 因及面积, 但本研究为重建过去的石漠化提供了可 能性.

致谢感谢西南大学蒋勇军教授、王宝艳硕士和卯杨硕 士提供的帮助以及李勇老师在本文对应的英文版语言上 的帮助. 我们也衷心感谢西南大学余金硕士提供历史资料.

\section{参考文献}

程海, 张海伟, 赵景耀, 李潮摸, 宁有丰, Kathayat G. 2019. 中国石笋 古气候研究的回顾与展望. 中国科学: 地球科学, 49: 1565-1589

程珂, 谢宇, 刘粤峰, 李汉杰, 潘晨光, 彭小桃, 刘淑华, 陈琼, 周厚云. 2019. 东亚季风区石笋 $\delta^{13} \mathrm{C}$ 是否记录植被变化: 从川东北石笋记 录的Heinrich事件说起. 第四纪研究, 39: 837-844

代谦, 别朝霞. 2015. 财政压力的经济后果: 以宋朝的“靖康之变”为 例. 世界经济, 38: 173-192

董春林. 2015. 以盐制夷: 宋代西南民族地区縻政策管窥. 广西民族 研究, 124: 135-142

方修琦, 苏笏, 尹君, 滕静超. 2015. 冷暖-丰羖-饥荒-农民起义: 基于 粮食安全的历史气候变化影响在中国社会系统中的传递. 中国 科学: 地球科学, 45: 831-842

郭纯青, 周䜭, 潘艳林. 2015. 中国西南岩溶区1900-2012年旱涝灾害 分析. 水资源与水工程学报, 26: 12-15

郭声波. 1988. 元明清时代四川盆地的农田剭殖. 中国历史地理论从, 4: $77-108$

蓝勇. 1997. 西南历史文化地理. 重庆: 西南大学出版社. 20-171

李北构. 1990. 关于贵州人口问题的历史、现状及对策. 贵州文史从 刊, 4: 121-132

李廷勇, 李红春, 向晓晶, 郭子兴, 李俊云, 周福莉, 陈虹莉, 彭玲莉. 2012. 碳同位素 $\left(\delta^{13} \mathrm{C}\right)$ 在重庆岩溶地区植被-土壤-基岩-洞穴系统 运移特征研究. 中国科学: 地球科学, 42: 526-535

李渊, 刘子琦, 吕小溪. 2016. 石漠化地区降雨条件下洞穴滴水时空
变化特征——贵州石将军洞为例. 西南大学学报, 38: 128-133 梁中效. 2004. 宋代蜀道城市与区域经济论述. 西南师范大学学报, 30: 95-100

罗旭玲, 王世杰, 白晓永, 谭秋, 苒晨, 陈欢, 习慧鹏, 陈飞, 操玥, 吴路 华, 李汇文, 钟昕. 2021. 西南喀斯特地区石漠化时空演变过程分 析. 生态学报, 41: 680-693

王世杰, 彭蹈, 刘再华, 倪健, 陈喜, 张信宝, 刘长成. 2020, 加强喀斯 特关键带长期观测研究, 支撑西南石漠化区生态恢复与民生改 善. 中国科学院院刊, 35: 925

韦启光. 1986. 贵州历史入口发展及其状况分析. 贵州文史从刊, 2: $11-16$

吴松弟. 2000. 中国人口史. 第三卷, 辽宋金元时期. 上海: 复旦大学 出版社. 314-500

吴松弟. 2001. 南宋人口的发展过程. 中国史研究, 4: 107-124

杨子慧. 1995. 中国历代人口统计资料研究. 北京: 改革出版社. 761777

张甘霖, 朱永官, 邵明安. 2019. 地球关键带过程与水土资源可持续 利用的机理. 中国科学: 地球科学, 49: 1945-1947

张善余. 1991. 中国历史人口周期性巨大波动的自然原因初探. 人口 研究, 5: 26-31

张世友, 彭福荣. 2012. 论两宋时期乌江流域人口流迁对民族交融的 推动. 贵州民族研究, 3: 122-127

张文. 2002. 两宋政府的少数民族赈济措施刍议——兼论宋朝民族 政策的转变倾向. 民族研究, 28: 124-130

张文. 2004. 两宋时期西南地区的民族冲突与社会控制. 西南师范大 学学报, 30: 102-107

赵文林. 1988. 中国人口史. 北京: 人民出版社

郑景云, 郝志新, 张学珍, 刘浩龙, 李明启, 葛全胜. 2014. 中国东部过 去2000年百年冷暖的旱涝格局. 科学通报, 59: 2964-2971

Abram N J, Wright N M, Ellis B, Dixon B C, Wurtzel J B, England M H, Ummenhofer C C, Philibosian B, Cahyarini S Y, Yu T L, Shen C C, Cheng H, Edwards R L, Heslop D. 2020. Coupling of IndoPacific climate variability over the last millennium. Nature, 579: 385-392

Bai X Y, Wang S J, Xiong K N. 2011. Assessing spatial-temporal evolution processes of karst rocky desertification land: Indications for restoration strategies. Land Degrad Develop, 24: 47-56

Bergel S J, Carlson P E, Larson T E, Wood C T, Johnson K R, Banner J L, Breecker D O. 2017. Constraining the subsoil carbon source to cave-air $\mathrm{CO}_{2}$ and speleothem calcite in central Texas. Geochim Cosmochim Acta, 217: 112-127

Chen J H, Chen F H, Feng S, Huang W, Liu J B, Zhou A F. 2015. Hydroclimatic changes in China and surroundings during the Medieval Climate Anomaly and Little Ice Age: Spatial patterns and possible mechanisms. Quat Sci Rev, 107: 98-111

Cheng H, Edwards R L, Shen C C, Polyak V J, Asmerom Y, Woodhead 
A D J, Hellstrom J, Wang Y, Kong X, Spötl C, Wang X, Calvin Alexander Jr. E. 2013. Improvements in ${ }^{230}$ Th dating, ${ }^{230} \mathrm{Th}$ and ${ }^{234} \mathrm{U}$ half-life values, and U-Th isotopic measurements by multi-collector inductively coupled plasma mass spectrometry. Earth Planet Sci Lett, 371-372: 82-91

Duan F C, Zhang Z Q, Wang Y, Chen J S, Liao Z B, Chen S T, Shao Q F, Zhao K. 2020. Hydrological variations in central China over the past millennium and their links to the tropical Pacific and North Atlantic oceans. Clim Past, 16: 475-485

Edwards R L, Chen J H, Wasserburg G J. $1987 .{ }^{238} \mathrm{U}_{-}{ }^{234} \mathrm{U}-{ }^{230} \mathrm{Th}^{-232} \mathrm{Th}$ systematics and the precise measurement of time over the past 500,000 years. Earth Planet Sci Lett, 81: 175-192

Etheridge D M, Steele L P, Langenfelds R L, Francey R J, Barnola J M, Morgan V I. 1996. Natural and anthropogenic changes in atmospheric $\mathrm{CO}_{2}$ over the last 1000 years from air in Antarctic ice and firn. J Geophys Res, 101: 4115-4128

Fairchild I J, Smith C L, Baker A, Fuller L, Spötl C, Mattey D, McDermott F, E.I.M.F. 2006. Modification and preservation of environmental signals in speleothems. Earth-Sci Rev, 75: 105-153

Fleitmann D, Burns S J, Mudelsee M, Neff U, Kramers J, Mangini A, Matter A. 2003. Holocene forcing of the Indian monsoon recorded in a stalagmite from southern Oman. Science, 300: 1737-1739

Fohlmeister J, Arps J, Spötl C, Schröder-Ritzrau A, Plessen B, Günter C, Frank N, Trüssel M. 2018. Carbon and oxygen isotope fractionation in the water-calcite-aragonite system. Geochim Cosmochim Acta, 235: 127-139

Gams I. 1991. Systems of adapting the littoral dinaric karst to agrarian land use. Acta Geogr, 31: 5-106

Ge Q S, Hao Z X, Zheng J Y, Shao X M. 2013. Temperature changes over the past $2000 \mathrm{yr}$ in China and comparison with the Northern Hemisphere. Clim Past, 9: 1153-1160

Hercman H, Pawlak J. 2012. MOD-AGE: An age-depth model construction algorithm. Quat Geochronol, 12: 1-10

Jaffey A H, Flynn K F, Glendenin L E, Bentley W C, Essling A M. 1971. Precision measurement of half-lives and specific activities of ${ }^{235} \mathrm{U}$ and ${ }^{238} \mathrm{U}$. Phys Rev C, 4: 1889-1906

Jiang Z, Lian Y, Qin X. 2014. Rocky desertification in Southwest China: Impacts, causes, and restoration. Earth-Sci Rev, 132: 1-12

Kathayat G, Cheng H, Sinha A, Liang Y, Li X L, Zhang H W, Li H Y, Ning Y F, Edwards R L. 2017. The Indian monsoon variability and civilization changes in the Indian subcontinent. Sci Adv, 3: e1701296

Kobashi T, Goto-Azuma K, Box J E, Gao C C, Nakaegawa T. 2012. Causes of Greenland temperature variability over the past $4000 \mathrm{yr}$ : Implications for northern Hemispheric temperature changes. Clim Past, 9: 2299-2317
Kuo T S, Liu Z Q, Li H C, Wan N J, Shen C C, Ku T L. 2011. Climate and environmental changes during the past millennium in central western Guizhou, China as recorded by Stalagmite ZJD-21. J Asian Earth Sci, 40: 1111-1120

Lan J H, Xu H, Lang Y C, Yu K K, Zhou P, Kang S G, Zhou K G, Wang X L, Wang T L, Cheng P, Yan D, Yu S Y, Che P, Ye Y, Tan L C. 2020. Dramatic weakening of the East Asian summer monsoon in northern China during the transition from the Medieval warm period to the Little ice age. Geology, 48: 307-312

Li H C, Lee Z H, Wan N J, Shen C C, Li T Y, Yuan D X, Chen Y H. 2011. The $\delta^{18} \mathrm{O}$ and $\delta^{13} \mathrm{C}$ records in an aragonite stalagmite from Furong Cave, Chongqing, China: A-2000-year record of monsoonal climate. J Asian Earth Sci, 40: 1121-1130

Li J Y, Li H C, Li T Y, Mii H S, Yu T L, Shen C C, Xu X. 2017. Highresolution $\delta^{18} \mathrm{O}$ and $\delta^{13} \mathrm{C}$ records of an AMS ${ }^{14} \mathrm{C}$ and ${ }^{230} \mathrm{Th} / \mathrm{U}$ dated stalagmite from Xinya Cave in Chongqing: Climate and vegetation change during the late Holocene. Quat Int, 447: 75-88

Li J Y, Li T Y. 2018. Seasonal and annual changes in soil/cave air $p \mathrm{CO}_{2}$ and the $\delta^{13} \mathrm{C}_{\mathrm{DIC}}$ of cave drip water in response to changes in temperature and rainfall. Appl Geochem, 93: 94-101

Li T Y, Huang C X, Tian L, Suarez M B, Gao Y. 2018. Variation of $\delta^{13} \mathrm{C}$ in plant-soil-cave systems in karst regions with different degrees of rocky desertification in Southwest China and implications for paleoenvironment reconstruction. J Cave Karst Stud, 80: $212-228$

Li T Y, Shen C C, Li H C, Li J Y, Chiang H W, Song S R, Yuan D X, Lin C D J, Gao P, Zhou L P, Wang J L, Ye M Y, Tang L L, Xie S Y. 2011. Oxygen and carbon isotopic systematics of aragonite speleothems and water in Furong Cave, Chongqing, China. Geochim Cosmochim Acta, 75: 4140-4156

Li T Y, Xiao S Y, Shen C C, Zhang J, Chen C J, Cheng H, Spötl C, Huang R, Wang T, Li J Y, Wu Y, Liu Z Q, Edwards R L, Yu T L. 2021. Little Ice Age climate changes in Southwest China from a stalagmite $\delta^{18} \mathrm{O}$ record. Palaeogeogr Palaeoclimatol Palaeoecol, 562: 110167

Li Y B, Shao J A, Yang H, Bai X Y. 2008. The relations between land use and karst rocky desertification in a typical karst area, China. Environ Geol, 57: 621-627

Liu D B, Wang Y J, Cheng H, Edwards R L, Kong X G, Li T Y. 2016. Strong coupling of centennial-scale changes of Asian monsoon and soil processes derived from stalagmite $\delta^{18} \mathrm{O}$ and $\delta^{13} \mathrm{C}$ records, southern China. Quat Res, 85: 333-346

Liu J B, Chen F H, Chen J H, Xia D S, Xu Q H, Wang Z L, Li Y C. 2011. Humid medieval warm period recorded by magnetic characteristics of sediments from Gonghai lake, Shanxi, north China. Chin Sci Bull, 56: 2464-2474 
Liu X K, Liu J B, Chen S Q, Chen J H, Zhang X, Yan J J, Chen F H. 2020. New insights on Chinese cave $\delta^{18} \mathrm{O}$ records and their paleoclimatic significance. Earth-Sci Rev, 207: 103216

Liu Z, Sun H, Li H, Wan N. 2011. $\delta^{13}$ C, $\delta^{18} \mathrm{O}$ and deposition rate of tufa in Xiangshui River, SW China: Implications for land-cover change caused by climate and human impact during the late Holocene. Geol Soc London Spec Publ, 352: 85-96

Liu Z Y, Wen X Y, Brady E C, Otto-Bliesner B, Yu G, Lu H Y, Cheng H, Wang Y J, Zheng W P, Ding Y H, Edwards R L, Cheng J, Liu W, Yang H. 2014. Chinese cave records and the east Asia summer monsoon. Quat Sci Rev, 83: 115-128

Polanski S, Fallah B, Befort D J, Pras A D S, Cubasch U. 2014 Regional moisture change over India during the past Millennium: A comparison of multi-proxy reconstructions and climate model simulations. Glob Planet Change, 122: 176-185

Polyak V J, Asmerom Y. 2001. Late Holocene climate and cultura changes in the southwestern United States. Science, 294: 148-151

Ruan J Y, Zhang H Y, Cai Z Y, Yang X Q, Yin J. 2019. Regional controls on daily to interannual variations of precipitation isotope ratios in southeast China: Implications for paleomonsoon reconstruction. Earth Planet Sci Lett, 527: 115794

Scroxton N, Burns S J, McGee D, Hardt B, Godfrey L R, Ranivoharimanana L, Faina P. 2017. Hemispherically in-phase precipitation variability over the last 1700 years in a Madagascar speleothem record. Quat Sci Rev, 164: 25-36

Shen C C, Wu C C, Cheng H, Edwards R L, Hsieh Y T, Gallet S, Chang C C, Li T Y, Lam D D, Kano A, Hori M, Spötl C. 2012. Highprecision and high-resolution carbonate ${ }^{230} \mathrm{Th}$ dating by MC-ICPMS with SEM protocols. Geochim Cosmochim Acta, 99: 71-86

Sinha A, Kathayat G, Weiss H, Li H Y, Cheng H, Reuter J, Schneider A W, Berkelhammer M, Adalı S F, Stott L D, Edwards R L. 2019. Role of climate in the rise and fall of the Neo-Assyrian Empire. Sci Adv, 5: eaax6656

Sun Q L, Liu Y, Wünnemann B, Peng Y J, Jiang X Z, Deng L J, Chen J, Li M T, Chen Z Y. 2019. Climate as a factor for Neolithic cultural collapses approximately 4000 years BP in China. Earth-Sci Rev, 197: 102915

Tan L C, Cai Y J, An Z, Cheng H, Shen C C, Breitenbach S F M, Gao Y, Edwards R L, Zhang H, Du Y. 2015. A Chinese cave links climate change, social impacts and human adaptation over the last 500 years. Sci Rep, 5: 12284

Tan L C, Cai Y J, Cheng H, Edwards L R, Lan J H, Zhang H W, Li D, Ma L, Zhao P P, Gao Y L. 2018. High resolution monsoon precipitation changes on southeastern Tibetan Plateau over the past 2300 years. Quat Sci Rev, 195: 122-132

Tan L, Shen C C, Löwemark L, Chawchai S, Edwards R L, Cai Y,
Breitenbach S F M, Cheng H, Chou Y C, Duerrast H, Partin J W, Cai W, Chabangborn A, Gao Y, Kwiecien O, Wu C C, Shi Z, Hsu H H, Wohlfarth B. 2019. Rainfall variations in central Indo-Pacific over the past 2,700 y. Proc Natl Acad Sci USA, 116: 17201-17206

Tarutani T, Clayton R N, Mayeda T K. 1969. The effect of polymorphism and magnesium substitution on oxygen isotope fractionation between calcium carbonate and water. Geochim Cosmochim Acta, 33: 987-996

Wang X F, Edwards R L, Auler A S, Cheng H, Kong X G, Wang Y J, Cruz F W, Dorale J A, Chiang H W. 2017. Hydroclimate changes across the Amazon lowlands over the past 45,000 years. Nature, 541: 204-207

Wang Y J, Cheng H, Edwards R L, An Z S, Wu J Y, Shen C C, Dorale J A. 2001. A high-resolution absolute-dated late Pleistocene monsoon record from Hulu Cave, China. Science, 294: 2345-2348

Wang Y J, Cheng H, Edwards R L, He Y Q, Kong X G, An Z S, Wu J Y, Kelly M J, Dykoski C A, Li X D. 2005. The Holocene Asian monsoon: Links to solar changes and North Atlantic climate. Science, 308: 854-857

Yan H, Sun L G, Wang Y H, Huang W, Qiu S C, Yang C Y. 2011. A record of the southern oscillation index for the past 2,000 years from precipitation proxies. Nat Geosci, 4: 611-614

Yassoglou N J. 2000. History of desertification in the European Mediterranean. In: Enne G, D’Angelo M, Zanolla C, eds. Indicators for Assessing Desertification in the Mediterranean. Proceedings of the International Seminar. Sassari: University of Sassari Nucleo Ricerca Desertificazion. 9-15

Yin J J, Li H C, Tang W, Wang Z, Mii H S, Lin Y. 2019. Rainfall variability and vegetation recovery in rocky desertification areas recorded in recently-deposited stalagmites from Guilin, South China. Quat Int, 528: 109-119

Yuan D X. 1997. Rock desertification in the subtropical karst of south China. Z Geomorph, 108: 81-90

Yuan D X, Cheng H, Edwards R L, Dykoski C A, Kelly M J, Zhang M L, Qing J M, Lin Y S, Wang Y J, Wu J Y, Dorale J A, An Z S, Cai Y J. 2004. Timing, duration, and transitions of the Last Interglacial Asian Monsoon. Science, 304: 575-578

Zeng S, Jiang Y, Liu Z. 2016. Assessment of climate impacts on the karst-related carbon sink in SW China using MPD and GIS. Glob Planet Change, 144: 171-181

Zhang H B, Griffiths M L, Chiang J C H, Kong W, Wu S, Atwood A, Huang J, Cheng H, Ning Y, Xie S. 2018. East Asian hydroclimate modulated by the position of the westerlies during termination I. Science, 362: 580-583

Zhang H W, Cai Y J, Tan L C, Cheng H, Qin S, An Z S, Edwards R L, Ma L. 2015. Large variations of $\delta^{13} \mathrm{C}$ values in stalagmites from 
southeastern China during historical times: Implications for anthropogenic deforestation. Boreas, 44: 511-525

Zhang M, Yuan D X, Lin Y, Qin J, Bin L, Cheng H, Edwards R L. 2004. A 6000-year high-resolution climatic record from a stalagmite in Xiangshui Cave, Guilin, China. Holocene, 14: 697-702

Zhang P Z, Cheng H, Edwards R L, Chen F H, Wang Y J, Yang X L, Liu J, Tan M, Wang X F, Liu J H, An C L, Dai Z B, Zhou J, Zhang D Z, Jia J H, Jin L Y, Johnson K R. 2008. A test of climate, sun, and culture relationships from an 1810-year Chinese cave record. Science, 322: 940-942

Zhang Q, Gemmer M, Chen J Q. 2008. Climate changes and flood/ drought risk in the Yangtze delta, China, during the past millennium. Quat Int, 176-177: 62-69
Zhao K, Wang Y, Edwards R L, Cheng H, Kong X G, Liu D B, Shao Q F, Cui Y F, Huang C C, Ning Y F, Yang X L. 2020. Late Holocene monsoon precipitation changes in southern China and their linkage to Northern Hemisphere temperature. Quat Sci Rev, 232: 106191

Zhao K, Wang Y J, Edwards R L, Cheng H, Liu D B, Kong X G. 2015. A high-resolved record of the Asian summer monsoon from Dongge cave, China for the past 1200 years. Quat Sci Rev, 122: 250-257

Zhao M, Li H C, Shen C C, Kang S C, Chou C Y. 2017. $\delta^{18} \mathrm{O}, \delta^{13} \mathrm{C}$, elemental content and depositional features of a stalagmite from Yelang Cave reflecting climate and vegetation changes since late Pleistocene in central Guizhou, China. Quat Int, 452: 102115

(责任编委: 鹿化显) 